\title{
STUDY OF LIQUID FILM BEHAVIOUR IN VERTICAL DOWNWARD AIR-WATER ANNULAR FLOW
}

\author{
YAGO RIVERA, JOSÉ LUIS MUÑOZ-COBO, CÉSAR BERNA, \\ ALBERTO ESCRIVÁ \& YAISEL CORDOVA \\ Instituto de Ingeniería Energética, Universitat Politècnica de Valencia, Spain
}

\begin{abstract}
The document collects the details of the GEPELON experimental installation (Ondulatory Film Generation), whose main goal is to measure and model downward air-water annular flow experiments. The facility has a length of $3.8 \mathrm{~m}$ and two test sections of $42 \mathrm{~mm}$ and $30 \mathrm{~mm}$ in diameter. Water is introduced through an injector with flow rates between $1-201 / \mathrm{min}$ and $1-10 \mathrm{l} / \mathrm{min}$ respectively. The air circuit provides flows between $0-2,500 \mathrm{l} / \mathrm{min}$, so it is possible to measure either vertical free fall or forced annular flow. Measurements of the liquid film thickness have been carried out using several conductance probes in different positions (both before and after the fluid development zone). The most important variables related to the liquid film thickness behaviour have been studied showing a strong dependence on the difference between air and liquid velocity.

Keywords: annular flow, free fall, disturbance waves, liquid film thickness, conductance probes.
\end{abstract}

\section{INTRODUCTION}

Liquid film systems falling down on surfaces constitute an important category within gasliquid systems that take advantage of gravity to achieve fluid movement. The existence of a liquid film sliding on the wall is essential to obtain a correct heat transfer coefficient. The development of surface waves at the interface between liquid and gas contribute to the appearance of eddies that increase the exchange of both heat and mass.

This small introduction tries to explain the interest of studying these types of systems not only in nuclear energy applications [1], [2], but also in numerous thermal systems such as capacitors, evaporators, refrigerators, distillation columns, chemical reactors, etc. [3]. Research in this field can also be applied to the validation of both CFD codes and thermohydraulic codes [4].

The main advantage of these systems over other configurations, such as forced flow in pressure ducts, is that they have a very good performance in heat transfer processes since they save on costs by not having to pump the flow through elements that produce high pressure drops (gravity itself is responsible for directing the flow), minimize thermal resistance to conduction in the film (especially for thin and laminar liquid films) and improve the transfer by capitalizing on turbulent eddies (especially for high liquid flow regimes in the film). They also improve heat transfer, between $40 \%$ and $80 \%$, due to surface waves that occur in the interface and also favour the exchange of mass between the film and the surrounding steam, and their passive character (gravity is the only force that drives these flows) makes them especially apt to guarantee the viability of nuclear energy in the future [5].

This study shows the results of the experiments carried out in the GEPELON installation (Ondulatory Film Generation). In the next section, the GEPELON facility is detailed, taking into account all the instrumentation that has been installed to measure both boundary conditions and liquid film thickness. Section 2 also describes the main characteristics of the liquid sensor, its electronics and the signal data processing. All the results are presented and discussed in Section 3 focusing on each specific variable that describes the water film. 
Finally, conclusions summarize all the main findings of this study and possible further investigation.

\section{EXPERIMENTAL SET-UP AND MEASUREMENT TECHNIQUE}

\subsection{Flow facility}

The experimental flow facility was designed to generate downward air-water annular flow along a vertical test section. The phenomena expected would be quite similar to the hydraulics behaviour of the passive refrigeration circuits of third generation nuclear reactors. The facility does not take into account the thermodynamics processes at this first stage.

Fig. 1 shows the flow diagram of the installation. The height of the facility test section is $3.8 \mathrm{~m}$ and there are two test sections with a diameter of $30 \mathrm{~mm}$ and $42 \mathrm{~mm}$. Two main circuits are part of the facility to control separately both air and water before being injected into the test section.

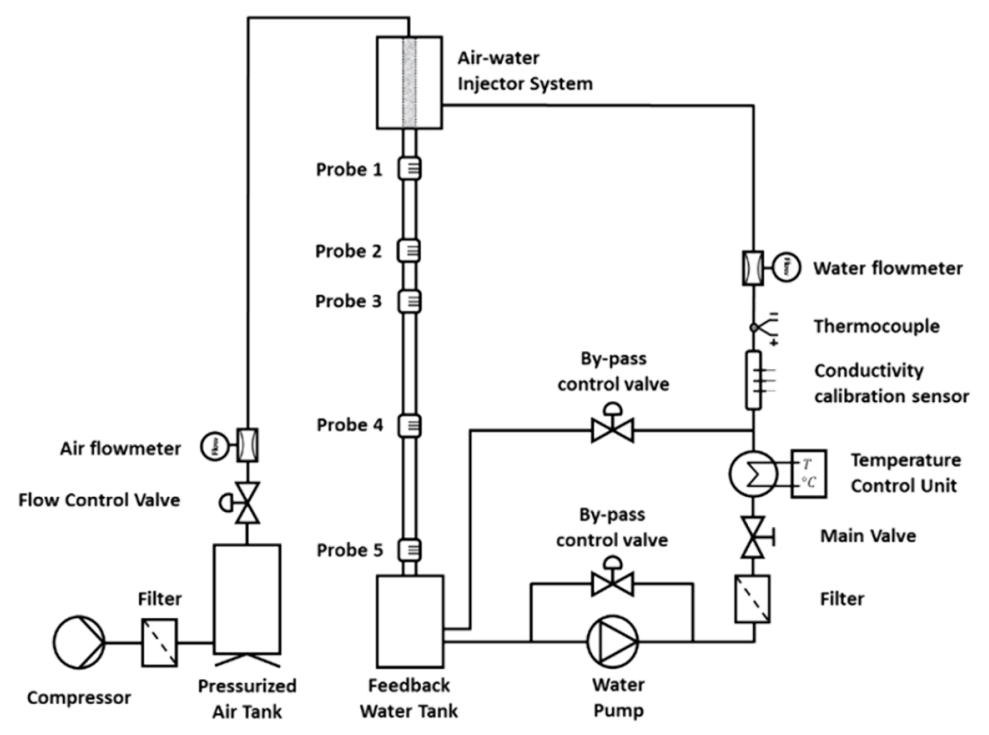

Figure 1: Flow diagram of the GEPELON facility (30 $\mathrm{mm}$ of internal diameter) equipped with five conductivity probes.

First, the water is pumped from the bottom tank to an injector located in the upper part of the installation. After entering the test section, the water film falls down the pipe (naturally or forced by the air) reaching the separation tank; where the loop starts again. The water is carefully treated before entering the loop and its properties are properly controlled.

Water goes through several devices on its way to the injector for both control and measurement. The water pump is controlled by an inverter that measures the water flow and changes the pump frequency by means of a PID controller. Temperature control station changes the water temperature if needed to maintain $21^{\circ} \mathrm{C}$ in the circuit. Several valves for water flow regulation and safety are installed and final temperature is measured. The conductivity calibration sensor shown in Fig. 1 measure the saturation voltage of the water and sends the value to the data acquisition (DAQ) program in order to adjust the calibration 
curve of the different probes. Any change in the water conductivity will be recorded by the conductivity calibration sensor before the measurements. Nevertheless, due to the high stability of the temperature obtained by the temperature control unit, conductivity does not change once stability conditions are reached.

On the other hand, air circuit is composed by the compressor, stabilization tank, safety and control valves and a flowmeter. Air flow is added to the water through a device called injector in the upper part of the facility. The injector has a sintered stainless steel pipe in the middle and water is pressurized around it. Depending on the characteristics of the sintered metal and the pressure, a specific flow will travel through the pipe joining the air flow coming from the upper inner part of the sintered pipe. Each test section $(42 \mathrm{~mm}$ and $30 \mathrm{~mm})$ has its own injector and sintered pipe with the same internal diameter as the test section. The pore size of the sintered stainless steel is $19 \cdot 10^{-6} \mathrm{~m}$ and the coefficient of viscous permeability, $y_{S}$, is $0.8 \cdot 10^{-12} \mathrm{~m}^{2}$. Both $42 \mathrm{~mm}$ and $30 \mathrm{~mm}$ test sections have a length of $3.8 \mathrm{~m}$ and each one has its own separation tank at the bottom.

\subsection{Experimental conditions}

A series of tests has been performed in each of the facilities, varying the measurement place and the flow rates of air/liquid. The measurements in the test section with $D=42 \mathrm{~mm}$ has been performed with three probes for a water flow range of 1-20 1/min while the measurements in the $30 \mathrm{~mm}$ pipe has been performed with five probes for a range of $1-10 \mathrm{l} / \mathrm{min}$. The air flow is the same for both diameters varying in the range of $0-2,500 \mathrm{l} / \mathrm{min}$. All these values can be easily converted into superficial velocities and Reynolds numbers in order to offer a more standard perspective of the experimental conditions.

Table 1 shows the different tests that have been performed in terms of flow, velocity and Reynolds numbers. It is worth to highlight that the superficial velocities are calculated supposing that the fluid fills the whole section of the pipe. Reynolds number should be also defined because sometimes the difference between superficial velocity Reynolds Number and liquid film Reynolds Number can lead to confusion. This document always shows the Reynolds Number calculated by means of the mean liquid film velocity and the film thickness $(\delta)$ as characteristic length (eqn 1)

$$
R e_{L}=\frac{\rho \cdot u_{L f} \cdot \delta}{\mu}=\frac{\rho \cdot Q}{\pi \cdot D \cdot \mu} .
$$

In short, the ranges covered are: liquid Reynolds $\left(R e_{L}\right)$ from 132 to 2,640 and gas Reynolds $\left(\operatorname{Re}_{G}\right)$ from $0-110,524$.

\subsection{Liquid sensor}

The most important element to accomplish the measurements in the GEPELON facility is the conductance probes represented in Fig. 2(a) and detailed in Muñoz-Cobo et al. [6] and Cuadros et al. [7]. These devices take advantage of the conductive properties of water to detect the film thickness near the wall.

Several authors have studied this type of sensor so its behaviour is very well known. The configuration of the electrodes that compose the probe can vary depending on the application and the resolution desired. All probes used in this study are "flush-mounted" and they usually work properly if the distance between electrodes is greater than the thickness of the liquid film [8]. Nevertheless, there are different configurations of conductance sensors for film thickness measurement. Damsohn and Prasser [9] studied different sensor characteristics, 
Table 1: Experimental conditions.

\begin{tabular}{|c|c|c|c|c|}
\hline \multicolumn{5}{|c|}{ Water setup range } \\
\hline $\begin{array}{c}\mathrm{Q}_{\mathrm{g}} \\
(\mathrm{l} / \mathrm{min})\end{array}$ & $\begin{array}{c}\mathrm{J}_{\mathrm{L}_{4} 42} \\
\mathrm{~mm} \\
(\mathrm{~m} / \mathrm{s})\end{array}$ & $\begin{array}{l}\mathrm{Re}_{42} \\
\mathrm{~mm}\end{array}$ & $\begin{array}{c}\mathrm{J}_{\mathrm{L}_{3} 30} \\
\mathrm{~mm} \\
(\mathrm{~m} / \mathrm{s})\end{array}$ & $\begin{array}{l}\mathrm{Re}_{30} \\
\mathrm{~mm}\end{array}$ \\
\hline 1 & 0.01 & 132 & 0.02 & 185 \\
\hline 2 & 0.02 & 264 & 0.05 & 370 \\
\hline 3 & 0.04 & 396 & 0.07 & 554 \\
\hline 4 & 0.05 & 528 & 0.09 & 739 \\
\hline 5 & 0.06 & 660 & 0.12 & 924 \\
\hline 6 & 0.07 & 792 & 0.14 & 1109 \\
\hline 7 & 0.08 & 924 & 0.17 & 1293 \\
\hline 8 & 0.10 & 1056 & 0.19 & 1478 \\
\hline 9 & 0.11 & 1188 & 0.21 & 1663 \\
\hline 10 & 0.12 & 1320 & 0.24 & 1848 \\
\hline 11 & 0.13 & 1452 & & \\
\hline 12 & 0.14 & 1584 & & \\
\hline 13 & 0.16 & 1716 & & \\
\hline 14 & 0.17 & 1848 & & \\
\hline 15 & 0.18 & 1980 & & \\
\hline 16 & 0.19 & 2112 & & \\
\hline 17 & 0.20 & 2244 & & \\
\hline 18 & 0.22 & 2376 & & \\
\hline 19 & 0.23 & 2508 & & \\
\hline 20 & 0.24 & 2640 & & \\
\hline
\end{tabular}

\begin{tabular}{|c|c|c|c|c|}
\hline \multicolumn{5}{|c|}{ Air setup range } \\
\hline $\begin{array}{c}\mathrm{Q}_{\mathrm{g}} \\
(\mathrm{l} / \mathrm{min})\end{array}$ & $\begin{array}{c}\mathrm{JG}_{-} 42 \\
\mathrm{~mm} \\
(\mathrm{~m} / \mathrm{s})\end{array}$ & $\begin{array}{c}\mathrm{Re}_{42} \\
\mathrm{~mm}\end{array}$ & $\begin{array}{c}\mathrm{J}_{\mathrm{G}_{-} 30} \\
\mathrm{~mm} \\
(\mathrm{~m} / \mathrm{s})\end{array}$ & $\begin{array}{c}\mathrm{Re}_{30} \\
\mathrm{~mm}\end{array}$ \\
\hline 0 & 0 & 0 & 0 & 0 \\
\hline 500 & 6.0 & 15789 & 11.8 & 22105 \\
\hline 1000 & 12.0 & 31578 & 23.6 & 44210 \\
\hline 1500 & 18.0 & 47368 & 35.4 & 66315 \\
\hline 2000 & 24.1 & 63157 & 47.2 & 88419 \\
\hline 2500 & 30.1 & 78946 & 58.9 & 110524 \\
\hline \multicolumn{7}{|c}{} \\
\hline
\end{tabular}

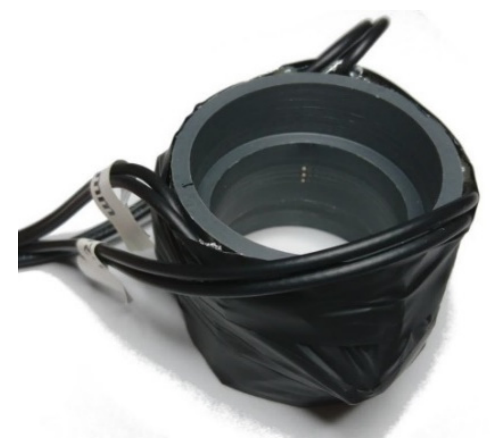

(a)

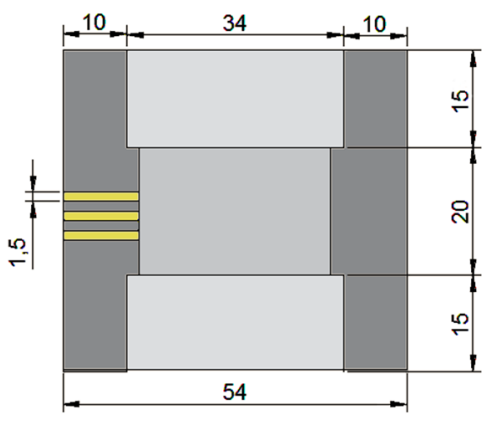

(b)

Figure 2: Conductance probe. (a) Real aspect; and (b) Longitudinal-section remarking the three flush-mounted electrodes (dimensions in $\mathrm{mm}$ ).

like area between electrodes, distance between them, shape, etc. Other authors, for instance Kulov et al. [10], measure the cross-sectional averaged film thickness by means of ring electrodes. This study is focus on the flush-mounted as they are reliable and easily configurable. 
Each probe consists of three $1.5 \mathrm{~mm}$ electrodes placed as shown in Fig. 2(b); one electrode to emit the signal, another to receive it and the last one grounded. In order to measure with this type of sensors it is necessary to design an electronic circuit (Fig. 3). The circuit will amplify, rectify and filter the signal that goes through the probe and finally, it will send the processed signal to the data acquisition system (DAQ).

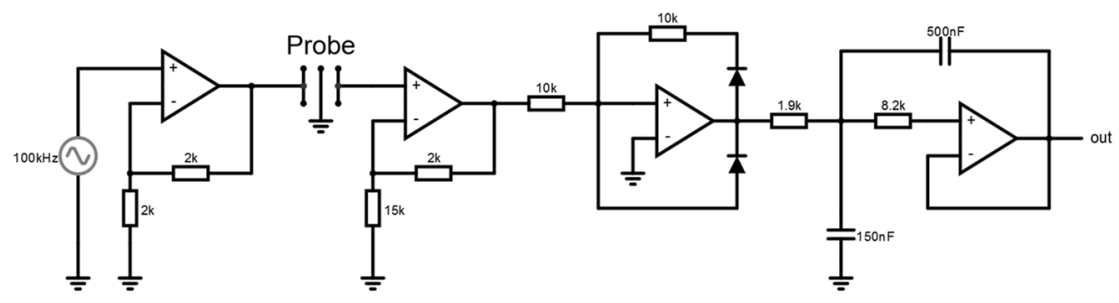

Figure 3: Electronic circuit for conductance sensors.

The raw signal registered in the database is in volts and does not directly provide information so it is necessary to pre-calibrate the probes to change between volts and film thickness (mm). In order to do the calibration, a new device has been developed composed of a high precision positioning system, several dielectric and calibrated cylinders, a signal generator, the probe electronics and the DAQ.

The GEPELON facility is equipped with eight of this conductance probes, five of them in the $30 \mathrm{~mm}$ test section and the remaining three in the $42 \mathrm{~mm}$ test section. The first one is located very close to the injection in order to detect the unperturbed flow. The film at this point is not developed so there are no disturbance waves. The second and the third one are located equidistant from the theoretical developed distance for free fall flow, after which the flow is fully developed according to Takahama and Kato [11] and Zadrazil and Markides [12]. For the $42 \mathrm{~mm}$ pipe there is only one before the theoretical disturbance waves. The fourth and fifth probes are in the developed zone. To better clarify this explanation, Fig. 4 shows the probe location in each test section and the corresponding relation between distance from the entrance and diameters.

One of the advantages of reducing the diameter of the pipe is the possibility of increasing the distance from the inlet, where the last probe is placed. When varying the inlet conditions (air and water flows) the required development distance could increase so the results in probes 4 and 5 for the $D_{\text {int }}=30 \mathrm{~mm}$ test section could be different.

\subsection{Data processing}

The signal from each probe recorded in the DAQ is processed through a Matlab® script. The code recognizes the air and water flows, boundary conditions, the probe number and it starts running. In order to remove noise and interferences, mainly coming from the grid $(50 \mathrm{~Hz}$ and harmonics), the raw signal is treated with a Savitzky-Golay filter of eight order [13]. After selecting the probe, the algorithm looks for its specific calibration curve to change between volts and film thickness in $\mathrm{mm}$. The curve is slightly modified following the instructions coming from the conductivity calibration sensor located at the water line after the pump.

Next, the algorithm starts looking for signal peaks and valleys to determine the disturbance waves. The function to select each peak takes into account three different restrictions. First, peaks should be higher than a minimum value, which is calculated 

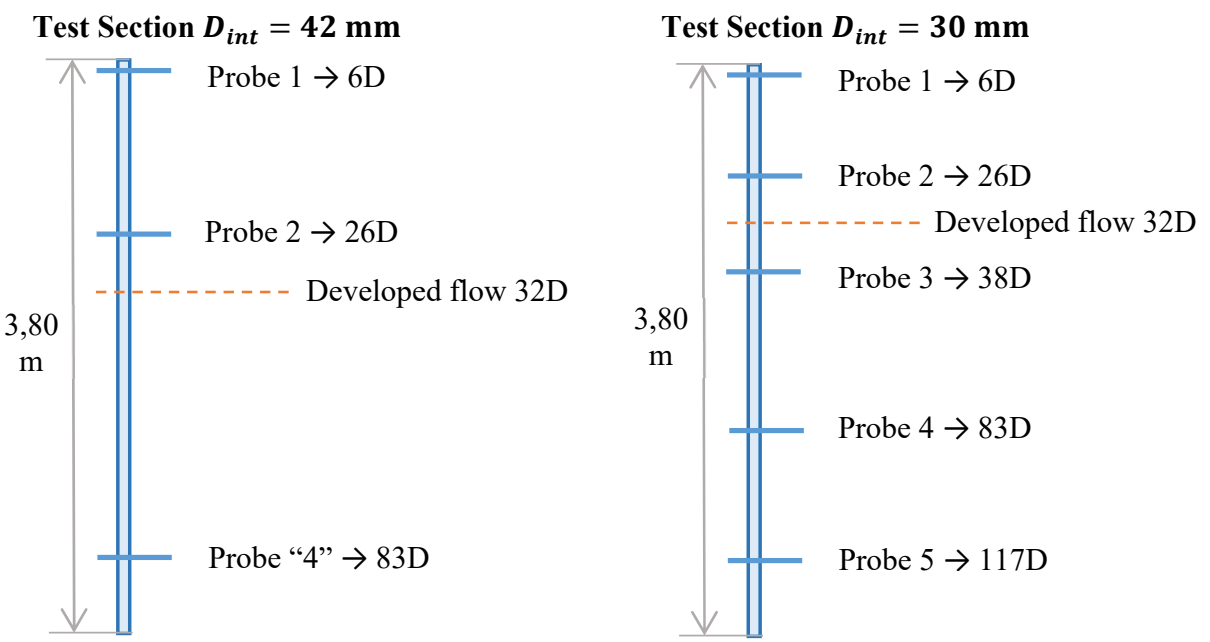

Figure 4: Location of the different conductance sensors.

considering the mean film thickness value (signal average). This minimum value is enough to remove the little peaks that appear between disturbance waves. Second restriction comes from a minimum distance between two consecutive peaks which allows to select just one peak of each wave. Finally, a prominence criterium has been imposed to select only the highest peak and eliminate adjacent ones that do not meet this condition.

Taking these peaks, the code calculates the different variables describing some of the most important characteristics of the downward air-water annular flow. To better understand which variables have been measured, Fig. 5 shows a scheme of them.

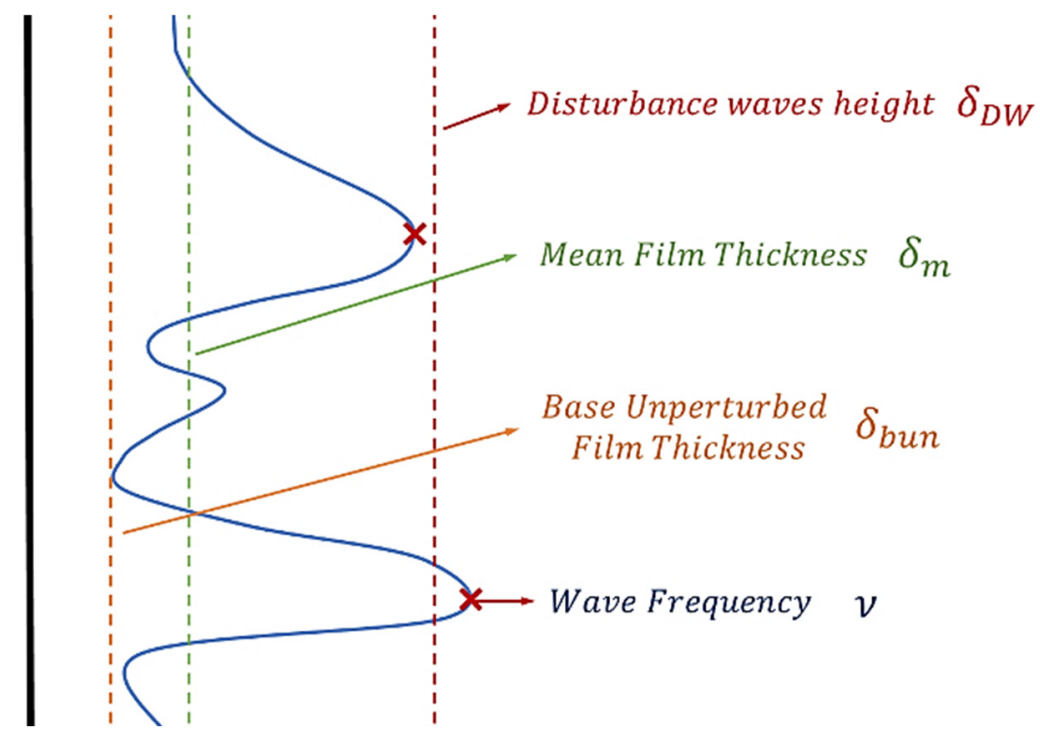

Figure 5: Definition of the studied variables. 
The mean film thickness $\left(\delta_{m}\right)$ correspond to the averaged measurement of all the recorded time of each boundary condition. After getting the peaks, the disturbance waves height $\left(\delta_{D W}\right)$ is calculated representing the average height of them. The base unperturbed film thickness $\left(\delta_{\text {bun }}\right)$ is defined as the average of the valleys obtained from the signal, giving the height where there is always water. Finally, the number of peaks divided by the time recorded corresponds to the disturbance wave frequency $(v)$. This study will focus on three of them: mean film thickness $\left(\delta_{m}\right)$, disturbance waves height $\left(\delta_{D W}\right)$ and wave frequency $(v)$.

\section{RESULTS AND DISCUSSION}

\subsection{Liquid film thickness measurements}

In this section, the measurements of the liquid film thickness through a conductance probe will be shown. Different inlet conditions will be compared to show its effect on the evolution of the sensor signal over time. The results will be a mix between both $30 \mathrm{~mm}$ and $42 \mathrm{~mm}$ pipe diameters for different Reynolds number. Therefore, a water flow of $10 \mathrm{l} / \mathrm{min}$ in the 42 $\mathrm{mm}$ pipe correspond to a water flow of approximately $7 \mathrm{l} / \mathrm{m}$ in the $30 \mathrm{~mm}$ pipe $(R e=1300)$.

Fig. 6 shows the evolution of the film thickness over time for different air and water Reynolds numbers in the zone of fully developed flow. From left to right each subplot shows increase in $R e_{L}$ and from top to bottom the growth corresponds to the $R e_{G}$. There is an increase in the film thickness measured by the probe as the $R e_{L}$ rise; and the opposite effect happens with the $R e_{G}$. Different authors have already detected the same behaviour both with conductance probes [14] and with other measurement methods [15], [16].

The following sections cover some of the most important variables of a liquid film: mean film thickness, disturbance wave height and frequency.

\subsection{Mean film thickness}

After treating the signal as described in Section 2.4 the mean film thickness $\left(\delta_{m}\right)$ is calculated. Fig. 7(a) confirms the increase in the mean liquid film thickness with the liquid Reynolds number mentioned in the previous section. The theoretical film thickness corresponds to the Nusselt equation $h_{0}=(3 \mu Q / 2 \pi r g \rho)^{1 / 3}$ that can be found in Nusselt [17]. The range of this equation is limited by a laminar regime and there are some forces not taken into account, so it is just a reference expected to be behind the real mean liquid film thickness. Probes 4 and 5 in the $30 \mathrm{~mm}$ installation shows that both of them are in the fully developed zone as the results are round about the same. On the other hand (Fig. 7(b)), when increasing the gas flow the mean film thickness starts to diminish following a nearly linear slope.

\subsection{Disturbance waves height}

The behaviour of the $\delta_{D W}$ is very close to the mean film thickness that causes the height to increase with $\operatorname{Re}_{L}$ (Fig. 8(a)). There are some boundary conditions where no peaks are detected for probes 1 or 2 as the flow is considered almost laminar. Probes 2 and 3, that located in the middle part of the pipe (Section 2.3 for more details), measure some sort of growing waves whose value is around half of the fully developed disturbance waves height.

As expected, $\delta_{D W}$ diminish when increasing the gas Reynolds number due to the effect of the shear stress produced by the gas on the waves (Fig. 8(b)). Nevertheless, the behaviour 

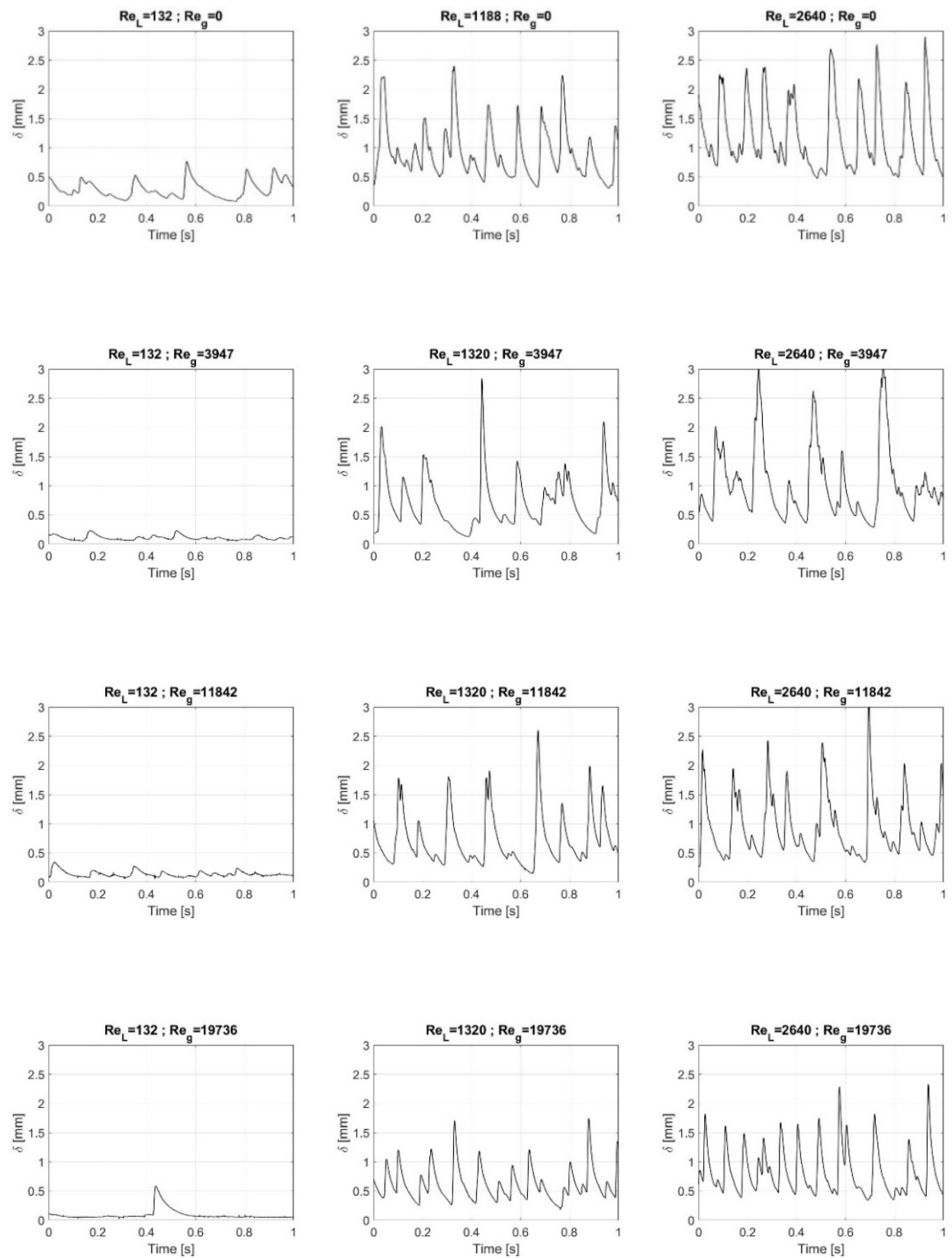

Figure 6: Film thickness versus time for different air-water Reynolds number values in the fully developed region. 


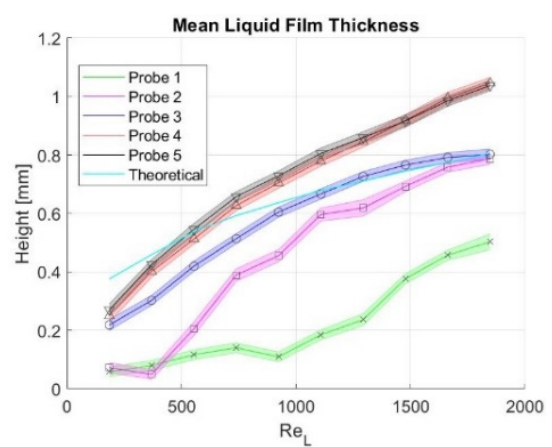

(a)

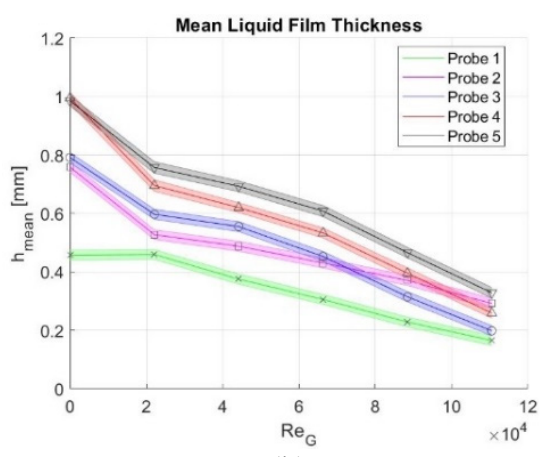

(b)

Figure 7: Mean film thickness $\delta_{m}$ evolution. (a) For different liquid Reynolds number and constant $R e_{G}=0$; and (b) For different gas Reynolds number and constant $R e_{L}=1600$.

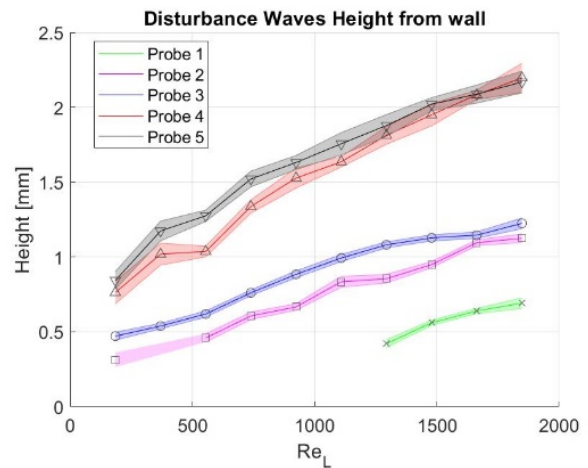

(a)

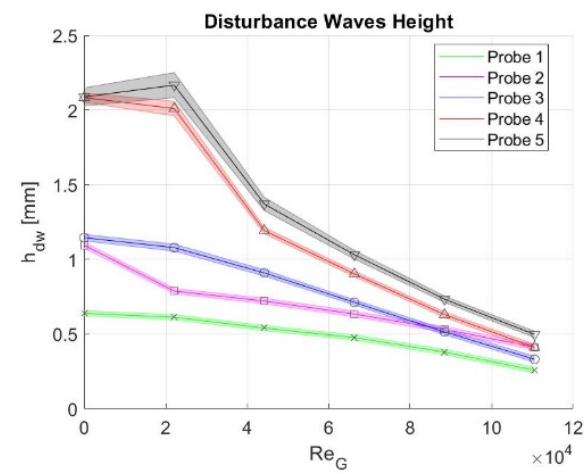

(b)

Figure 8: Disturbance waves height $\delta_{D W}$ evolution. (a) For different liquid Reynolds number and constant $R e_{G}=0$; and (b) For different gas Reynolds number and constant $R e_{L}=1,600$.

of the disturbance waves height is not that simple because it appears a maximum near the lowest measured gas Reynolds number, the same one observed by Zadrazil et al. [15]. This maximum could be related with the differences of the velocity between the disturbance waves and the gas.

The wave movement is caused mainly because of the effect of the gravity and the shear stress so it is expected to be a balance between these two forces. At $R e_{G}=0$ the gravity impulses the film, but the shear stress tries to reduce the movement as the gas is motionless. At a specific $R e_{G}$ around 20000, the gas is flowing at the same velocity as the disturbance waves so the friction between them is negligible and the height is maximum. Following this reasoning, from this critical value the velocity difference increases the shear stress in the interface so the disturbance waves height begins to increase again. 


\subsection{Frequency}

Measuring the frequency by means of the peaks is not the best methodology because the waves are no linear and they are also different in height between them. Nevertheless, it is a good reference of the global wave frequency and allows to see tendencies. Fig. 9(a) shows the evolution of the frequency when increasing the liquid Reynolds number. Frequency appear to increase following the same behaviour as the mean liquid film thickness but with a more pronounced asymptote at around $11 \mathrm{~Hz}$ for all the measurements at $R e_{G}=0$.

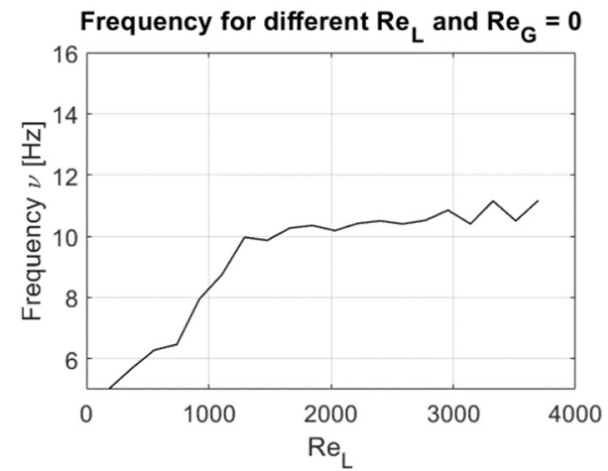

(a)

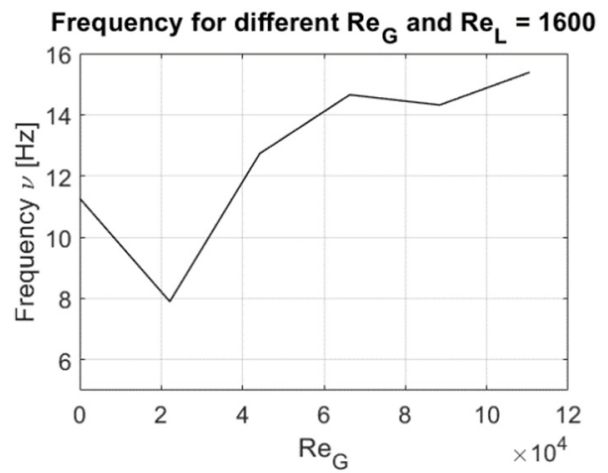

(b)

Figure 9: Frequency $v$ evolution of the fully developed disturbance waves. (a) For different liquid Reynolds Number and constant $R e_{G}=0$; and (b) For different gas Reynolds number and constant $R e_{L}=1,600$.

Following the reasoning given in Section 3.3 for the disturbance waves height, the frequency reaches a minimum at a critical gas Reynolds number around 20,000 (Fig. 9(b)). If the conditions are close to the critical gas Reynolds number, the waves have the maximum height in exchange for a smaller number of them. This global effect can be slightly seen in Fig. 6 where the second row of graphs has fewer waves although they are higher than the other ones.

\section{CONCLUSIONS}

A technique with minimal intrusivity by means of conductance probes was used to measure the liquid film thickness in a downward air-water annular flow facility. A total of 180 experiments have been carried out in two different pipes (42 $\mathrm{mm}$ and $30 \mathrm{~mm}$ of diameter). Measurements have been done through eight conductance probes located in different positions along the tube allowing to measure developing and fully developed flow. Three main characteristic variables have been considered in this study: mean film thickness $\left(\delta_{m}\right)$, disturbance waves height $\left(\delta_{D W}\right)$ and wave frequency $(v)$. Measurements reveal that both mean film thickness and disturbance waves height increase when the water Reynolds number increases. On the other hand, these two variables decrease if the air flow rate increase, as it is expected. Frequency increases quite similar to the disturbance waves height but it reaches a maximum (asymptote) earlier when increasing the water Reynolds number. A critical gas Reynolds number have been detected at around $R e_{L}=20,000$ mainly due to the effect of the velocity difference between the air and the wavy interface. Both of them are flowing at a 
similar velocity allowing the appearance of a maximum in the disturbance waves height and a minimum in its frequency. In the future, our investigation will be focused on finding reliable correlations which takes into account this critical gas Reynolds number. To achieve this goal, Weber number will be used including the difference between air and water velocity $\left(W e^{*}=\left(\rho \cdot\left(u_{L f}-u_{G}\right)^{2} \cdot D\right) / \sigma\right)$. Also, it is expected to compare the results obtained in GEPELON facility with equivalent measurements using Particle Image Velocimetry (PIV) or another alternative methodology.

\section{ACKNOWLEDGEMENT}

The authors would like to thank the support of the National Research Agency of Spain for the EXMOTRANSIN project, ENE2016-79489-C2-1-P.

\section{REFERENCES}

[1] Alekseenko, S.V., Antipin, V.A., Cherdantsev, A.V., Kharlamov, S.M. \& Markovich, D.M., Investigation of waves interaction in annular gas-liquid flow using high-speed fluorescent visualization technique. Microgravity Science and Technology, 20(3-4), pp. 271-275, 2008.

[2] Ju, P., Yang, X., Schlegel, J.P., Liu, Y., Hibiki, T. \& Ishii, M., Average liquid film thickness of annular air-water two-phase flow in $8 \times 8$ rod bundle. International Journal of Heat and Fluid Flow, 73, pp. 63-73, 2018.

[3] Ho, C.D., Chang, H., Chen, H.J., Chang, C.L., Li, H.H. \& Chang, Y.Y., CFD simulation of the two-phase flow for a falling film microreactor. International Journal of Heat and Mass Transfer, 54(15-16), pp. 3740-3748, 2011.

[4] Ghosh, S., Das, G. \& Das, P.K., Simulation of core annular downflow through CFD: A comprehensive study. Chemical Engineering and Processing: Process Intensification, 49(11), pp. 1222-1228, 2010.

[5] Berna, C., Escrivá, A., Muñoz-Cobo, J.L. \& Herranz, L.E., Review of droplet entrainment in annular flow: Interfacial waves and onset of entrainment. Progress in Nuclear Energy, 74, pp. 14-43, 2014.

[6] Muñoz-Cobo, J. et al., Development of conductivity sensors for multi-phase flow local measurements at the Polytechnic University of Valencia (UPV) and University Jaume I of Castellon (UJI). Sensors, 17(5), p. 1077, 2017.

[7] Cuadros, J.L. et al., Characterization of the gas-liquid interfacial waves in vertical upward co-current annular flows. Nuclear Engineering and Design, 346, pp. 112-130, 2019.

[8] Coney, M.W.E., The theory and application of conductance probes for the measurement of liquid film thickness in two-phase flow. Journal of Physics E: Scientific Instruments, 6(9), p. 903, 1973.

[9] Damsohn, M. \& Prasser, H.M., High-speed liquid film sensor for two-phase flows with high spatial resolution based on electrical conductance. Flow Measurement and Instrumentation, 20(1), pp. 1-14, 2009.

[10] Kulov, N.N., Maksimov, V.V., Maljusov, V.A. \& Zhavoronkov, N.M., Pressure drop, mean film thickness and entrainment in downward two-phase flow. Chemical Engineering Journal, 18(2), pp. 183-188, 1979.

[11] Takahama, H. \& Kato, S. Longitudinal flow characteristics of vertically falling liquid films without concurrent gas flow. International Journal of Multiphase Flow, 6, pp. 203-215, 1979. 
[12] Zadrazil, I. \& Markides, C.N., An experimental characterization of liquid films in downwards co-current gas-liquid annular flow by particle image and tracking velocimetry. International Journal of Multiphase Flow, 67(S), pp. 42-53, 2014.

[13] Savitzky, A. \& Golay, M.J.E., Smoothing and differentiation of data by simplified least squares procedures. Analytical Chemistry, 36(8), pp. 1627-1639, 1964.

[14] Almabrok, A.A., Aliyu, A.M., Lao, L. \& Yeung, H. Gas/liquid flow behaviours in a downward section of large diameter vertical serpentine pipes. International Journal of Multiphase Flow, 78, pp. 25-43, 2016.

[15] Zadrazil, I., Matar, O.K. \& Markides, C.N., An experimental characterization of downwards gas-liquid annular flow by laser-induced fluorescence: Flow regimes and film statistics. International Journal of Multiphase Flow, 60, pp. 87-102, 2014.

[16] Pan, L., He, H., Ju, P., Hibiki, T. \& Ishii, M., Experimental study and modeling of disturbance wave height of vertical annular flow. International Journal of Heat and Mass Transfer, 89, pp. 165-175, 2015.

[17] Nusselt, W., Die oberflächenkondensation des wasserdampfes. Zeitschrift des Vereines Dtsch. Ingenieure, 60, pp. 541-546, pp. 569-575, 1916. 